\title{
Clinical Reasoning: Immunocompetent patient with multiple cranial nerve palsies, ataxia, and cognitive decline
}

Minali Nigam, BA, Michael Wang, MD, and Leah Commander, MD

Neurology ${ }^{\circledR}$ 2020;94:e225-e229. doi:10.1212/WNL.0000000000008793
Correspondence

Minali Nigam

minali_nigam@med.unc.edu

\section{Section 1}

A 71-year-old woman with a 4-month history of recurrent headaches refractory to treatment presented to her primary care physician's office with persistent headaches, generalized weakness, and a droopy left eyelid. During initial hospital assessment, she endorsed a 20-pound weight loss. She denied any fever, neck stiffness, or photophobia. Her medical history was significant for type II diabetes mellitus and hypertension (both well-controlled and off medications).

On examination, the patient was alert and oriented to person, place, and time. Her speech was dysarthric and she had difficulty with word-finding and following 2-step commands. Pupils were $3 \mathrm{~mm}$ and equally reactive to light. She had complete ptosis of the left eyelid, and her left eye was down and out at rest. The left eye was able to abduct and look down, but unable to adduct. The right eye was able to abduct and look down, but unable to go past midline when adducting. Upward gaze was limited in both eyes. Eyelid closure was weak bilaterally, but weaker on the left. Facial sensation to light touch was decreased in the V2 distribution bilaterally, and the patient also exhibited mild left facial droop. Hearing was intact. Shoulder shrug was intact. No palate or tongue weakness/asymmetry was noted. Strength in upper and lower limbs was $5 / 5$ throughout. Deep tendon reflexes were 2+ and symmetric throughout. Toes were downgoing bilaterally. Sensation to light touch, pinprick, and temperature was intact on the right side, but diminished in the left arm and leg throughout and did not fit with a peripheral nerve distribution. Truncal ataxia was noted when sitting up and walking. She had an unsteady, wide-based gait, and her balance did not worsen with eyes closed.

\section{Question for consideration:}

1. What is the differential diagnosis for this patient?

GO TO SECTION 2 


\section{Section 2}

The patient was independent and healthy before onset of her headaches. She worked as a cardiovascular technician and was an avid gardener. She also often remodeled her house, where she had lived for many years. She was HIV-negative and had no history of atypical infections or immunocompromised status.

Given multiple cranial nerve $(\mathrm{CN})$ palsies (bilateral CN III, bilateral CN V, bilateral CN VII), diminished sensation on the left arm and leg, cognitive decline, and ataxia on examination, in addition to weight loss and recurrent headaches, the patient likely had an ongoing intracranial pathology. Multiple etiologies could account for $\mathrm{CN}$ involvement, mental status changes, sensory loss, and ataxia, including malignancy or metastasis (high on differential with age, weight loss, and subacute presentation); infection (given recurrent headaches and possible indolent presentation that could explain lack of fever or meningeal signs); inflammatory/autoimmune disease (sarcoidosis, Behçet disease, amyloidosis, or acute inflammatory demyelinating polyneuropathy that could present with multiple $\mathrm{CN}$ involvement); ischemic stroke in brainstem (given diminished left-sided sensation and $\mathrm{CN}$ palsies); and vascular malformations (aneurysm or vertebrobasilar dolichoectasia that could present with multiple $\mathrm{CN}$ neuropathy).

\section{Question for consideration:}

1. What diagnostic testing is needed?

GO TO SECTION 3 


\section{Section 3}

A comprehensive, systematic work-up, including imaging, repeated lumbar puncture (LP), and blood tests, is necessary when considering etiologies such as malignancy or infectious, autoimmune, or ischemic conditions.

\section{Imaging}

An MRI of the brain showed multiple foci of leptomeningeal nodular enhancement of the brainstem and cerebellum. It also showed multiple acute infarcts within the midbrain and pons (figure 1). MRI of the cervical spine without contrast showed no hyperintensity within the visualized portion of the cord. MRI of the abdomen/pelvis with and without contrast showed a 4-mm punctate $\mathrm{T} 2$ hyperintensity in the pancreatic body. CT head, magnetic resonance angiography head, and chest X-ray were unremarkable.

\section{Lumbar puncture}

All LPs were performed under fluoroscopy. Opening pressures were not documented.

1. Results of first LP: colorless, $21 \mu \mathrm{L}$ red blood cells, 289-313 $\mu \mathrm{L}$ nucleated cells, $45 \%$ neutrophils, $55 \%$ lymphocytes, 434 $\mathrm{mg} / \mathrm{dL}$ protein, $34 \mathrm{mg} / \mathrm{dL}$ glucose; cytology negative, no culture growth, no organisms on Gram stain, cryptococcal antigen not tested

2. Results of second LP: straw color, $1 \mu \mathrm{L}$ red blood cells, 100-238 $\mu \mathrm{L}$ nucleated cells, $29 \%$, neutrophils, $68 \%$ lymphocytes, $2 \%$ monocytes/macrophages, $442 \mathrm{mg} / \mathrm{dL}$ protein, $<20 \mathrm{mg} / \mathrm{dL}$ glucose; cytology performed and showed atypical cells, but these cells were poorly preserved due to mechanical distortion in laboratory, no culture growth, no organisms on Gram stain, cryptococcal antigen not tested

3. Results of third LP: straw color, $13 \mu \mathrm{L}$ red blood cells, 248 $\mu \mathrm{L}$ nucleated cells, $39 \%$ neutrophils, $55 \%$ lymphocytes, $6 \%$ monocytes/macrophages, $429 \mathrm{mg} / \mathrm{dL}$ protein, $33 \mathrm{mg} / \mathrm{dL}$ glucose, cryptococcal antigen positive (1:10 titer); cytology not tested, no culture growth, no organisms on Gram stain, negative fungal culture

Overall: CSF with lymphocytic pleocytosis, hypoglycorrhachia, increased protein, positive cryptococcal antigen.

\section{Blood tests}

White blood cell count was normal. The patient's low-density lipoprotein was 131 and A1c 6.2. Cryptococcal antigen in serum was positive with titer 1:80.

Figure $1 \mathrm{MRI}$ brain shows leptomeningeal enhancement and infarcts

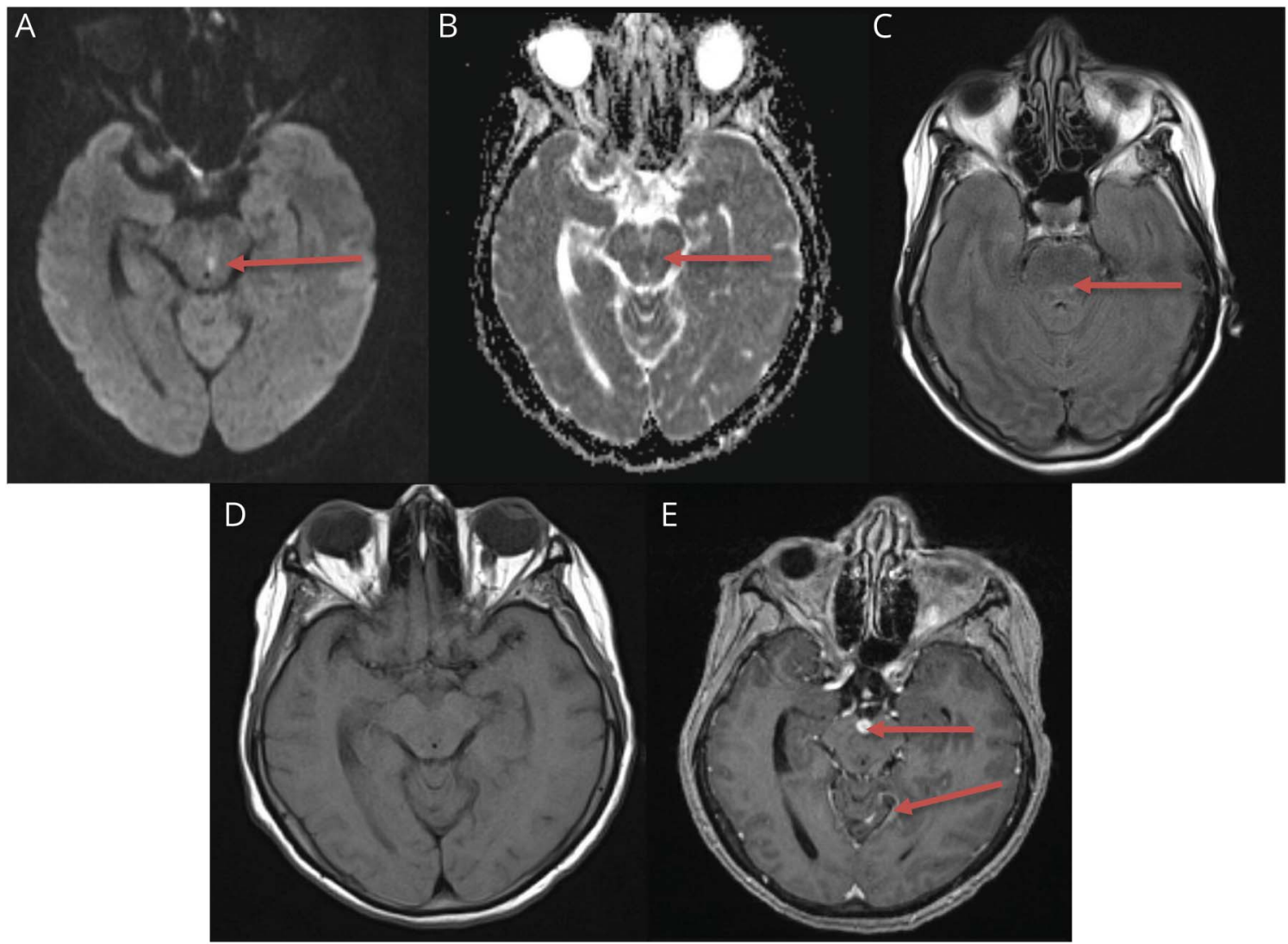

(A) Diffusion-weighted imaging shows midbrain infarct. (B) Apparent diffusion coefficient shows midbrain infarct. (C) Fluid-attenuated inversion recovery shows pontine infarct. (D) Precontrast T1 and (E) postcontrast T1 show leptomeningeal enhancement in brainstem and cerebellum. 


\section{Bone scan}

PET CT showed L3 pedicle lesion suspicious for malignancy. Biopsy showed findings of granuloma and fungal elements with appearance of Cryptococcus. Staining was confirmatory with positive Grocott methenamine silver (GMS)-F, negative acid-fast bacilli, and mucicarmine highlight of capsule (figure 2).

\section{Diagnosis}

While leptomeningeal carcinomatosis was initially suspected due to the presence of leptomeningeal enhancement on MRI, extensive workup revealed CSF containing nucleated cells and hypoglycorrhachia, positive cryptococcal antigen in blood and CSF, and L3 pedicle biopsy showing fungal elements that stained for GMS and mucicarmine. The patient was diagnosed with cryptococcal meningitis and was started on amphotericin and flucytosine.

\section{Discussion}

Cryptococcal meningitis is relatively rare among previously healthy individuals, with approximately 3,000 immunocompetent cases reported annually in the United States. ${ }^{1}$ Headache is the most common presenting symptom, although fever, vomiting, and altered mental status can also be observed. ${ }^{2,3} \mathrm{Im}$ munocompetent patients with cryptococcal meningitis are more likely to have subacute, recurrent episodes of nonspecific symptoms like headache, nausea, and $\mathrm{CN}$ palsies. ${ }^{4}$ Other signs include meningismus, papilledema, focal deficits, and depressed level of consciousness. ${ }^{5}$ Our patient had recurrent headaches prior to her $\mathrm{CN}$ palsies and ataxia.

Cryptococcus neoformans and Cryptococcus gattii are 2 different species that can cause meningitis, with $C$ gattii increasingly seen in immunocompetent patients. ${ }^{3}$ The infection is acquired through inhalation of spores, often found in soil contaminated with avian excreta. After entering the lungs, the organism can eventually spread via hematogenous dissemination, penetrating the meningeal vessel walls and subarachnoid space, before manifesting as subacute meningoecephalitis. ${ }^{4-6}$ Notable exposures for this patient include soil exposure as an avid gardener or possible mold exposure during house remodeling.

Cryptococcus can cause infarction, usually in the basal ganglia, internal capsule, or thalamus. Progressive spread of meningeal inflammation affecting blood vessels can lead to constriction or thrombosis and subsequent stroke. ${ }^{2}$ The patient's hospital course was complicated by a fall and new stroke found in the right caudate and left thalamus, possibly a result of her infection. She was started on aspirin and statin while on antifungals.

There are no pathognomonic brain imaging findings for cryptococcal meningitis. MRI can show leptomeningeal enhancement, infarctions in basal ganglia/thalamus, nodules, granulomas, or hydrocephalus, among other nonspecific findings. ${ }^{5}$ Furthermore, there are no specific imaging differences between immunocompetent and immunocompromised patients with cryptococcal meningitis. ${ }^{7}$ The polysaccharide capsule is the major virulence factor and substrate detected by cryptococcal antigen testing. CSF in HIV-negative patients is likely to show lymphocytic pleiocytosis, elevated protein, and low glucose. While India ink staining is highly specific, it has lower sensitivity than cryptococcal antigen testing, which is why we did not include India ink staining in the patient's workup. ${ }^{8}$ In immunocompetent patients, cultures and antigen tests in CSF can be negative and the diagnosis can be difficult to exclude, in which case serial large-volume LPs may be necessary. ${ }^{5}$

Elevated opening pressures should be aggressively controlled with repeated LPs and large volume CSF drainage. Daily therapeutic LPs should be performed until opening pressures normalize, a method that has shown survival benefit. ${ }^{9}$ Because

Figure 2 Pathology from L3 pedicle lesion
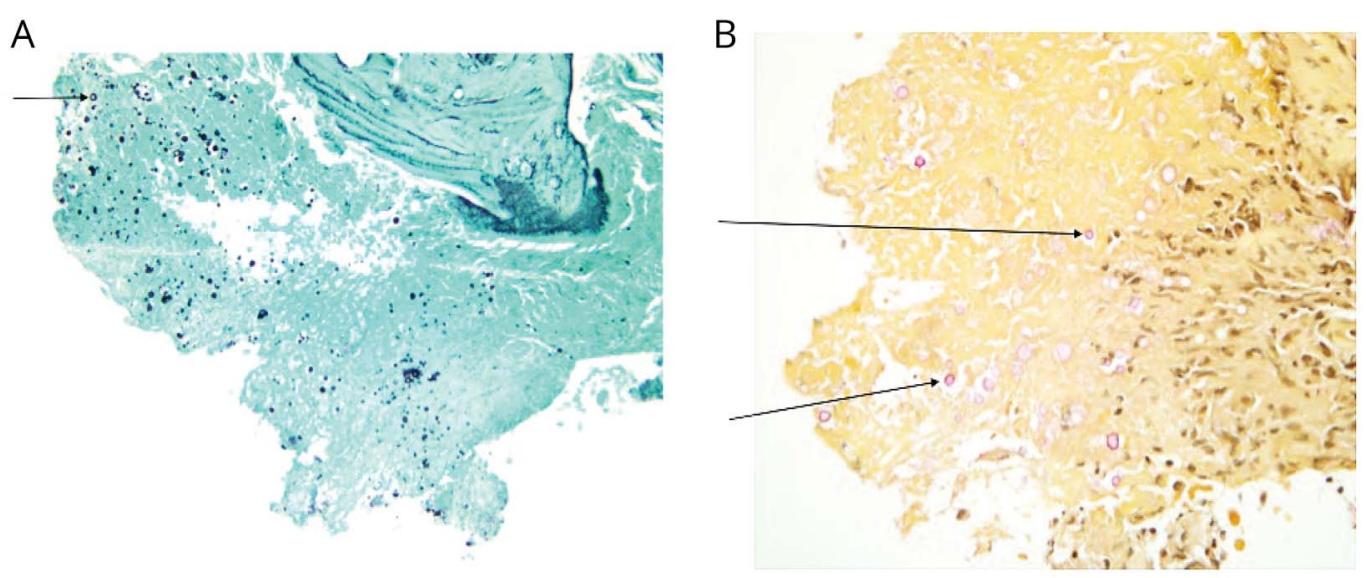

(A) Positive Grocott methenamine silver stain highlights fungal elements in black (10× magnification). (B) Positive mucicarmine stain outlines cryptococcal capsule in magenta (20x magnification). 
cryptococcal meningitis was not as high on our initial differential, we did not consider checking opening pressures during our 3 diagnostic LPs for this patient, a limitation of this case study.

Treatment for non-HIV-infected, nontransplant patients includes amphotericin (0.7-1.0 mg/kg per day IV) and flucytosine (100 mg/kg per day orally) for at least 4 weeks of induction therapy in patients without neurologic complications. ${ }^{1,10}$ In immunocompetent patients with neurologic complications, extended induction therapy is needed for 6 weeks before starting consolidation with $800 \mathrm{mg}$ fluconazole daily for 8 weeks. Fluconazole $200 \mathrm{mg}$ daily for 6-12 months is the mainstay for maintenance therapy. ${ }^{10}$ Our patient was started on amphotericin and flucytosine for 6 weeks. Her headache, CN palsies, sensory loss, and ataxia improved. She was transitioned to fluconazole for an 8-week course of consolidation, followed by fluconazole $200 \mathrm{mg}$ to complete a 12-month course of maintenance therapy. Mental status, appetite, and ability to ambulate improved during maintenance therapy.

Although this patient did not have any evidence of fever or meningeal signs, we had a low threshold to test for cryptococcal meningitis. In immunocompetent patients who have recurrent headaches, altered mental status, multiple $\mathrm{CN}$ palsies, or ataxia, cryptococcal meningitis should be considered, especially given curability of the disease.

\section{Study funding}

No targeted funding reported.

\section{Disclosure}

The authors report no disclosures relevant to the manuscript. Go to Neurology.org/N for full disclosures.
Appendix Authors

\begin{tabular}{|c|c|c|c|}
\hline Name & Location & Role & Contribution \\
\hline $\begin{array}{l}\text { Minali } \\
\text { Nigam, BA }\end{array}$ & $\begin{array}{l}\text { University of } \\
\text { North } \\
\text { Carolina, } \\
\text { Chapel Hill }\end{array}$ & Author & $\begin{array}{l}\text { Drafted the initial } \\
\text { manuscript, revised the } \\
\text { manuscript, involved in } \\
\text { clinical care of the patient }\end{array}$ \\
\hline $\begin{array}{l}\text { Michael } \\
\text { Wang, MD }\end{array}$ & $\begin{array}{l}\text { University of } \\
\text { North } \\
\text { Carolina, } \\
\text { Chapel Hill }\end{array}$ & Author & $\begin{array}{l}\text { Revised the manuscript, } \\
\text { involved in clinical care of } \\
\text { the patient }\end{array}$ \\
\hline $\begin{array}{l}\text { Leah } \\
\text { Commander, } \\
\text { MD }\end{array}$ & $\begin{array}{l}\text { University of } \\
\text { North } \\
\text { Carolina, } \\
\text { Chapel Hill }\end{array}$ & Author & $\begin{array}{l}\text { Revised the manuscript, } \\
\text { involved in clinical care of } \\
\text { the patient }\end{array}$ \\
\hline
\end{tabular}

\section{References}

1. Williamson PR, Jarvis JN, Panackal AA, et al. Cryptococcal meningitis: epidemiology, immunology, diagnosis and therapy. Nat Rev Neurol 2017;13:13-24.

2. Mishra AK, Arvind VH, Muliyil D, et al. Cerebrovascular injury in cryptococcal meningitis. Int J Stroke 2018;13:57-65.

3. Mitchell DH, Sorrell TC, Allworth AM, et al. Cryptococcal disease of the CNS in immunocompetent hosts: influence of cryptococcal variety on clinical manifestations and outcome. Clin Infect Dis 1995;20:611-616.

4. Merkler AE, Gaines N, Baradaran H, et al. Direct invasion of the optic nerves, chiasm, and tracts by Cryptococcus neoformans in an immunocompetent host. Neurohospitalist $2015 ; 5: 217-222$.

5. Bicanic T, Harrison TS. Cryptococcal meningitis. Br Med Bull 2004;72:99-118.

6. Liyanage DS, Pathberiya LP, Gooneratne IK, et al. Cryptococcal meningitis presenting with bilateral complete ophthalmoplegia: a case report. BMC Res Notes 2014; $7: 328$.

7. Duarte SBL, Oshima MM, Mesquita JV, et al. Magnetic resonance imaging findings in central nervous system cryptococcosis: comparison between immunocompetent and immunocompromised patients. Radiol Bras 2017;50:359-365.

8. Dominic RS, Prashanth $\mathrm{H}$, Shenoy S, et al. Diagnostic value of latex agglutination in cryptococcal meningitis. J Lab Physicians 2009;1:67-68.

9. Abassi M, Boulware DR, Rhein J. Cryptococcal meningitis: diagnosis and management update. Curr Trop Med Rep 2015;2:90-99.

10. Perfect JR, Dismukes WE, Dromer F, et al. Clinical practice guidelines for the management of cryptococcal disease: 2010 update by the infectious diseases Society of America. Clin Infect Dis 2010;50:291-322. 


\section{Neurology}

\section{Clinical Reasoning: Immunocompetent patient with multiple cranial nerve palsies, ataxia, and cognitive decline \\ Minali Nigam, Michael Wang and Leah Commander \\ Neurology 2020;94;e225-e229 \\ DOI 10.1212/WNL.0000000000008793}

This information is current as of January 13, 2020

Updated Information \& Services

References

Subspecialty Collections

Permissions \& Licensing

Reprints including high resolution figures, can be found at: http://n.neurology.org/content/94/2/e225.full

This article cites 10 articles, 0 of which you can access for free at: http://n.neurology.org/content/94/2/e225.full\#ref-list-1

This article, along with others on similar topics, appears in the following collection(s):

All Clinical Neurology

http://n.neurology.org/cgi/collection/all_clinical_neurology All Infections

http://n.neurology.org/cgi/collection/all_infections

All Neuro-ophthalmology

http://n.neurology.org/cgi/collection/all_neuroophthalmology

Fungal infections

http://n.neurology.org/cgi/collection/fungal_infections

Gait disorders/ataxia

http://n.neurology.org/cgi/collection/gait_disorders_ataxia

Information about reproducing this article in parts (figures,tables) or in its entirety can be found online at:

http://www.neurology.org/about/about_the_journal\#permissions

Information about ordering reprints can be found online:

http://n.neurology.org/subscribers/advertise

Neurology ${ }^{\circledR}$ is the official journal of the American Academy of Neurology. Published continuously since 1951, it is now a weekly with 48 issues per year. Copyright @ 2020 American Academy of Neurology. All rights reserved. Print ISSN: 0028-3878. Online ISSN: 1526-632X.

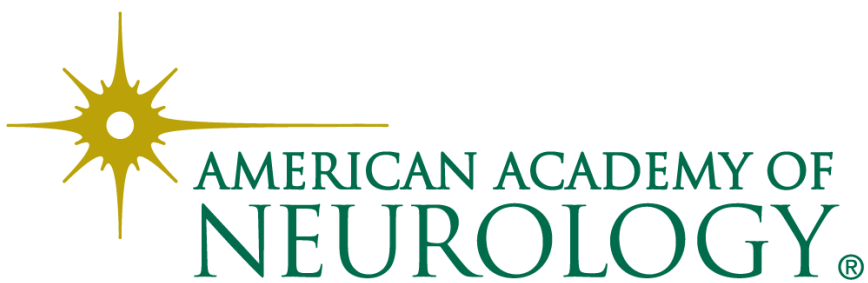

